\title{
Behavioral context of blue and fin whale calling for density estimation
}

\author{
Ana Širović \\ Scripps Institution of Oceanography, UCSD \\ 9500 Gilman Drive MC 0205 \\ La Jolla, CA 92093-0205 \\ phone: (858) 534-8036 email: asirovic@ucsd.edu \\ John Calambokidis \\ Cascadia Research Collective \\ 218 1/2 West 4th Avenue \\ Olympia, WA 98501 \\ phone: (360) 943-7325 email: calambokidis@cascadiaresearch.org
}

Award Number: N000141410414

\section{LONG-TERM GOALS}

This is the first annual report for this project, in which we will determine the context-appropriate call production rates for blue and fin whales in the Southern California Bight, with the end goal of facilitating density estimation from passive acoustic data.

\section{OBJECTIVES}

Before a reliable estimate of blue and fin whale call production rates can be developed for use in density estimation, we must understand the factors that influence calling rates (e.g. season, sex, behavioral state, time of day, group association, dive behavior, etc.). For this project, we will use previously collected tag data to determine the context-specific call production rates for blue and fin whales. In addition, we will elucidate gaps in the data which may affect our ability to develop a comprehensive behavioral model of calling, develop a strategy for filling those gaps, and conduct field data collection to address some gaps in the data coverage for these species.

\section{APPROACH}

We will focus on the current main gap in density estimation process using passive acoustic data, the estimation of the average call production rate. We will use blue whales (Balaenoptera musculus) and fin whales (B. physalus) as our model species because, as endangered species that are common in many areas of naval activity, they are of special interest to the Navy. In the case of blue whales, there exists already a relatively large data set relevant to answering the question of their call rate production, while the data on fin whales are scarce. We will develop both the conceptual framework for analyzing these types of data and appropriate call rate models, as well as collecting additional data that will enable us to increase the robustness of these call rate models. In general, our approach can be broken down into four components: analysis of available tag data, analysis of data gaps, passive acoustic analysis, and field sampling efforts. 


\section{Report Documentation Page}

Form Approved

OMB No. 0704-0188

Public reporting burden for the collection of information is estimated to average 1 hour per response, including the time for reviewing instructions, searching existing data sources, gathering and maintaining the data needed, and completing and reviewing the collection of information. Send comments regarding this burden estimate or any other aspect of this collection of information,

including suggestions for reducing this burden, to Washington Headquarters Services, Directorate for Information Operations and Reports, 1215 Jefferson Davis Highway, Suite 1204, Arlington

VA 22202-4302. Respondents should be aware that notwithstanding any other provision of law, no person shall be subject to a penalty for failing to comply with a collection of information if it

does not display a currently valid OMB control number.

1. REPORT DATE

30 SEP 2014

4. TITLE AND SUBTITLE

Behavioral Context of Blue and Fin Whale Calling for Density Estimation

6. $\operatorname{AUTHOR}(\mathrm{S})$

7. PERFORMING ORGANIZATION NAME(S) AND ADDRESS(ES)

University of California San Diego,Scripps Institution of Oceanography,9500 Gilman Drive,La Jolla,CA,92093

9. SPONSORING/MONITORING AGENCY NAME(S) AND ADDRESS(ES)

3. DATES COVERED

00-00-2014 to 00-00-2014

5a. CONTRACT NUMBER

5b. GRANT NUMBER

5c. PROGRAM ELEMENT NUMBER

5d. PROJECT NUMBER

5e. TASK NUMBER

5f. WORK UNIT NUMBER

8. PERFORMING ORGANIZATION

REPORT NUMBER

10. SPONSOR/MONITOR'S ACRONYM(S)

11. SPONSOR/MONITOR'S REPORT

NUMBER(S)

12. DISTRIBUTION/AVAILABILITY STATEMENT

Approved for public release; distribution unlimited

13. SUPPLEMENTARY NOTES

14. ABSTRACT

15. SUBJECT TERMS

16. SECURITY CLASSIFICATION OF:

a. REPORT

unclassified b. ABSTRACT

unclassified c. THIS PAGE

unclassified
17. LIMITATION OF ABSTRACT

Same as

Report (SAR)
18. NUMBER 19a. NAME OF

OF PAGES RESPONSIBLE PERSON

3 


\section{Analysis of available tag data}

Available for this analysis are acoustic data collected by the Cascadia Research Collective (CRC) and the Scripps Institution of Oceanography (SIO) since 2002 from tags deployed on blue and fin whales for multiple projects, including the recent behavioral response studies (Southern California Behavioral Response Study, SOCAL-BRS, and Office of Naval Research (ONR) funded work on blue whale response to ship noise). Acoustic tags have been successfully deployed on approximately 150 blue whales, with most deployment occurring between June and October off the coast of California. The number of successful acoustic tag deployments on fin whales is much smaller, approximately 20 tags from the SCB in summer months. We will use only deployments with more than 15 min of high quality acoustic data collected for the analysis to avoid biasing the data with a possible response of the whale to the tagging event rather than its true behavior.

Deployment of acoustic recording tags that will be used in this analysis was conducted for a variety of research reasons. While all acoustic recording tags were attached without a priori knowledge of the whale's vocal behavior, different attachments were targeting animals in specific behavioral states or under different environmental and geographic conditions. Thus our collection of tag data cannot be considered a random sample of the population. We will use a variety of behavioral and geographic parameters to stratify our data in an effort to account for the biases in the collected data, as well as elucidate gaps in the existing data. We will then build models of calling using these different parameters to evaluate their impact on changes in call rates.

\section{Analysis of data gaps}

In addition to temporal gaps in the data, possibly the largest bias in our blue whale data set stems from the data collection that was addressing a variety of research questions and targeting animals in different behavioral and geographic settings. These settings can be separated into four dominant categories:

1) Coastal feeding aggregations, represented by animals that were tagged close to shore and were often in larger feeding groups, which represent a large fraction of the SOCAL-BRS effort

2) Southern California offshore animals, which were tagged to address questions specifically relating to calling animals and thus represent a sample that is likely skewed towards callers

3) Coastal callers were animals sampled during the same effort as 2 above, but they were found much closer to shore

4) Low density are animals found in dispersed mode and these individuals were the ones most commonly tagged during the ship strike tagging effort

\section{Passive acoustic analysis}

To address the geographical sampling bias in our data set and evaluate the calling preference of inshore and offshore animals off Southern California described in section Analysis of data gaps above, we will use passive acoustic data previously recorded by High-frequency Acoustic Recording Packages (HARPs) deployed inshore and offshore of Channel Islands. To evaluate how similar the calling is at the two different sites, we will manually detect all A, B, and D calls and calculate the ratio of A calls to B calls, and B calls to D calls at each site over this time. Call rates of each call type will be normalized by the detection range calculated separately for each site and call type. Based on the results of that test, we may be able to pool the two data sets from Southern California offshore animals and coastal callers ( 2 and 3 in section above) into a single behavioral setting category "callers," which would provide a 
larger sample size for that category. We expect to apply a comparable spatial stratification to the fin whale $20 \mathrm{~Hz}$ and $40 \mathrm{~Hz}$ call data to potentially enable pooling of fin whale tag data.

\section{Field work}

We will conduct two field sampling campaigns to address known data gaps. In particular, we will undertake field campaigns that augment the current data sets, but also complement other currently underway tagging efforts such as the ONR funded blue whale ship-strike work (PI Calambokidis). Some of the gaps we plan to address with these additional tagging efforts include lack of springtime data, limited spatial coverage, as well as lack of nighttime deployment to address any diel changes in behavior and calling, in addition to addressing the contextual biases in earlier tagging efforts. New developments in potential longer applications of archival tags are being tested in 2014 and we will seek to adapt these to some of the additional planned acoustic tag deployments in the future. This sampling effort will provide longer term records of call production less biased by tagging location and activity, with better sampling of vocal activity at night. We will target both blue and fin whales in these field efforts that will likely focus in northern Mexico and the SCB and we will couple tagging efforts with passive acoustic data collection.

\section{WORK COMPLETED}

- Analysis of blue whale A, B, and D call presence at two sites (one inshore and one offshore) in the SCB from one year of data, for investigations into the spatial variability of the behavioral state of animals.

- We have started discussions with the SOCAL-BRS team about analysis of the call records from acoustic tags deployed in that project.

\section{RESULTS}

This is the first annual report and the grant was awarded only in June 2014, thus there are no significant results to report at this point.

\section{IMPACT/APPLICATIONS}

Call rate estimates developed by this method will be of wide use to research areas of Navy interest. For example, these rates will be easily applicable to blue whale recordings collected by other researchers conducting work in the eastern North Pacific Ocean to develop regional and seasonal blue whale density estimates and will thus offer input for enhancing wider Navy monitoring efforts. In addition, it will be possible to use information on blue and fin whale call rates as a baseline for studies on the effects of noise on blue and fin whale calling behavior in this region.

\section{RELATED PROJECTS}

We are coordinating with other funded projects on density estimation using passive acoustics including "Large scale density estimation of blue and fin whales" (PI Dr. Miksis-Olds) and "Cheap DECAF: Density Estimation for Cetaceans from Acoustic Fixed sensors using separate, non-linked devices" (PI Dr. Thomas). Additionally, we expect to benefit from the data collection underway under ONR funded projects "Behavioral and physiological response of baleen whales to ships and ship noise" (PI Calambokidis), as well as the SOCAL-BRS tagging efforts. 